International Journal of Business and Management 4 (3): 14-21, 2020

e-ISSN: 2590-3721

(C) RMP Publications, 2020

DOI: $10.26666 / \mathrm{rmp} . \mathrm{ijbm} .2020 .3 .3$

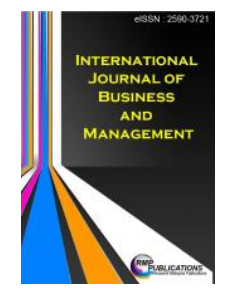

\title{
Mobile Technology and Organizational Culture: The Challenges of Using Mobile Instant Messaging for Managing Work in the Malaysian Army
}

\author{
Saiful Azuwar, Shamshul Bahri \\ Department of Operation \& Management Information Systems, Faculty of Business \& Accountancy, \\ University of Malaya, Malaysia
}

\begin{abstract}
Mobile technology is one of the most favoured communication platforms in modern organizations. However, the organizations facing challenges in utilizing this technology and have given little regard to the possible setbacks of its usage. In the Army, the use of mobile instant messaging (MIM) may create conflicts with its command function, the flow of information, work focus, and military doctrines and values. The paper explains the nature of organizational communication in the Malaysian Army and the challenges of MIM usage in the Army working environment in the context of organizational culture. The findings based on the case study on the suitability of MIM usage in the Malaysian Army. Twelve Army officers from the ranks of Major and Lieutenant Colonel were selected for semi-structured interviews. The study discovers that military organization is a unique entity that having its own norms of work and social relationship and the values of the Army should be preserved during communication. The paper ends with recommendations to commanders and managers in the Army on how the technology should be utilized at the workplace.
\end{abstract}

Keywords: Organizational communication, mobile technology, organizational culture, mobile instant messaging, Malaysian Army

\section{INTRODUCTION}

The rapid development in mobile technology has transformed the way personnel communicates in organizations, including in the Army organization. Mobile instant messaging (MIM) has become an important communication option for modern military personnel, particularly for sharing information, coordinating their works, and chatting with multiple users simultaneously. MIM such as WhatsApp and Telegram are becoming more popular and become the favourite medium for people to communicate [1].

With the Malaysian Army's wide distribution of units and formations, the communication between officers and personnel is crucial to achieve the Army's objectives. The military personnel's communication in the Army organization is determined by their positions and which activities they belong to. In formal settings, Army personnel communicates through their chain of command. The commander regularly communicates verbally through telephone, radio network, and face-to-face interactions or written through official letters and emails. The same mode of communication applies when soldiers communicate with their officers and commanders. Meanwhile social platforms such as chat groups are used in informal or casual settings, mainly to share or disseminate information and ideas.

The use of mobile technology has changed the nature of communication among commanders, officers, and soldiers. Commanders instantly distribute important documents to troops through smartphones and internet media [2]. There are also innumerable non-tactical methods communicated through text messages with seniors [3]. MIM demolishes the barrier in the military hierarchy when the information can flow in various directions. There is also concern about the work socialization impact in using mobile technology such as MIM which also affected the Army culture.

Even though MIM offers the fast transmission of messages, this technology raises the issue of work efficiency [4], smartphone addiction, and deviation to non-work-related activities [5]. The technology also distracts focus at the workplace [6] and becoming a concern to the managers. Anyhow, the phenomenon is understudied in the military environment and there is a lack of guidelines and

Corresponding Author: Shamshul Bahri, Department of Operation \& Management Information Systems, Faculty of Business \& Accountancy, University of Malaya. 50630 Kuala Lumpur, Malaysia, E-mail: esbi@um.edu.my 
procedures to dictate how mobile technology should be applied to avoid ramifications with military doctrines and values.

Despite the changes in communication brought by mobile technology and all its possible impacts, very little knowledge is available on how the Malaysian Army should manage its usage to suit with military culture. Currently, the technologies are used widely with very little regards on its suitability in the context of the Army official usage. Each activity in the Army demands different approaches in using communication media based on interoperability, working environment, and security [7] and this is also applying for MIM.

In understanding the concept of culture, it refers to share values that determine the patterns of behaviour in a group [8]. The topic of culture is highly relevant in information systems research [9]. It is a complex and intangible phenomenon [10] and most of the definitions cover culture as shared values and norms [11]. The discussions and understanding of culture were made in the context. For this study, the Malaysian Army context is applied.

\section{LITERATURE REVIEW}

\section{The Emergence of Mobile Communication Technology in Organization}

Communication is an interactive process to improve collaboration among members of an organization. The process is facilitated through various tools, from an informal chat among colleagues to a formal corporate communication from executives [12]. The selection of an appropriate communication platform contributes significantly to an organization's success and helps employees perform better [13]. Effective governance that welcomes the use of digital technologies can lead to effective and accurate dissemination of organization ideas [14]. Instead, strict application of the technology may lead to dissatisfaction, frustration, and demotivation [15].

However, the selection of an appropriate communication platform presents a huge challenge to organizations [16]. The organization needs to balance the need for good communication practices among employees while ensuring that organizational goals are reached [17]. To do so, they have to strive for two-way communication where employees can engage effectively in the organization's decision-making process [18]. Organizations are also finding it difficult to replicate face-to-face communication in situations where it is not possible [19].
The emergence of new communication technologies such as online social networking platform has made the task of selecting the most appropriate communication platform for an organization more complicated. Although mobile messaging such as MIM is first developed as social communication platforms, they have been increasingly adopted by organization for use in formal situations [20]. The application of social technologies for organizational communication can present its own difficulties and challenges. Among them are threats of information leakages and misinterpretation [21]. Some of the features also unfit with the organization culture.

With the advancement of technology and the decrease in cost of mobile platforms, MIM has been the tool of choice for users to instantly exchange messages [22]. There are several reasons for MIM popularity. Its interface is well-designed for convenience and interactivity [23]. The technology also has temporal and multimodal features [24]. Beside text chats, there are voice and video calls, images, emoticons, and audio/video messages and often used in combination [25]. Two of the most frequent features used to represent expression in MIM are emoticons and photos [26]. The available languages, figures, and symbols enable users to express meaning, thus enhancing mutual understanding [25]. MIM has also included the ability to share real-time information with users' contacts individually or in groups [27].

Mobile communication technologies enhanced the quality of people's daily interaction and assist them in daily routines such as updating information with others, managing work and coordination of daily activities [28]. The emergence of mobile technologies offers flexibility and convenience for mobile users where users can engage in many activities simultaneously [29]. They can communicate with others anywhere in real-time by using the same free-of-charge applications in their smartphones [30]. MIM fulfils people's personal interests and needs. It is used used regularly at the workplace [31].

The use of mobile technology in communication also reduces the need for face-to-face interaction [18]. The cost of having face-to-face meetings in the organization were reduced. Additionally, the technology brings the casual mode of communication presents in the social realm to the workplace. As a result, users are freely express themselves compared to other platforms that are considered more formal [32]. The expressions and emotions of a user represent by the emoticons and symbols that are available in the mobile technology features [33]. Anyhow, the scarcity of non-verbal 
signs such as gestures and body language in the MIM accepted by scholars even though it is useful. The use of MIM at the workplace presents issues in terms of usage and socialization. The technology may interrupt employees' focus because it can be used simultaneously with non-work-related activities [34]. As a result, productivity is affected as tasks will take longer to complete [4]. The huge number of messages received during working hours may lead to information overload that affects job satisfaction [35]. The long hours spent on the smartphone could lead to smartphone addiction [5]. On the other hand, the extensive use of MIM at the workplace may make users susceptible to information leakages [34]. The exposure to many online activities by using Internet communication medium will expose users to unintended leakage of confidential information.

\section{Adapting Military Culture in Organizational Communication}

Mobile communication technology has also been increasingly used in the Malaysian Army. Currently, it is widely used in the education and learning process for combat [36]. Countries such as Singapore and United States also allow the use of mobile technology by their soldiers to assist their work during operational duties. Nevertheless, the ability of the technology to penetrate more activities in the Army depends on their interoperability requirements, working environment, and security [7]. In the Army, confidentiality and security are vital to meet the intelligence requirement of the organization [37] and it is also becoming concern in the use of mobile technology in communication.

Organizational communication is also influenced by the culture of the organization. The culture consists of norms and values that are complex and intangible. These norms and values influence the selection of a communication platform and how it is accepted to be used in the organization [38]. The military organization also having its own culture; which consists of norms and values that influence the use of communication technology for military use. The developments in communication technology need to integrate with the doctrine, organization, and tactics of the Army work environment [39].

The culture in the military organization in the context of communication can be seen in a few perspectives. The perspectives to be discussed in this paper are the superior-subordinates relationship, the military doctrines, the regimental values, and the staff duties requirements. All these four perspectives are part of the Army norms and values that are accepted as a culture in the military organization. This culture shapes the conduct and behaviour of the Army personnel in their daily working activities. As mention, it is accepted by all organization's members.

\section{Superior-subordinates relationship}

Communication in the military bound with the nature of the military superior-subordinates relationship. Superior-subordinates relationship is crucial for organizational success especially in the formal environment [40]. In the Army organization, the formal superior-subordinates relationship observed in most of the activities such as instructortrainees relationship at the training area and the superior-subordinates relationship in the operation area. The relationship is formal and authorized by the military rules. All types of communication in the military bound with this superior-subordinates requirement in the command system. In the Army command system, the ranks are categorized into three levels; top management, middle management and supervisory as shown in Figure 1.

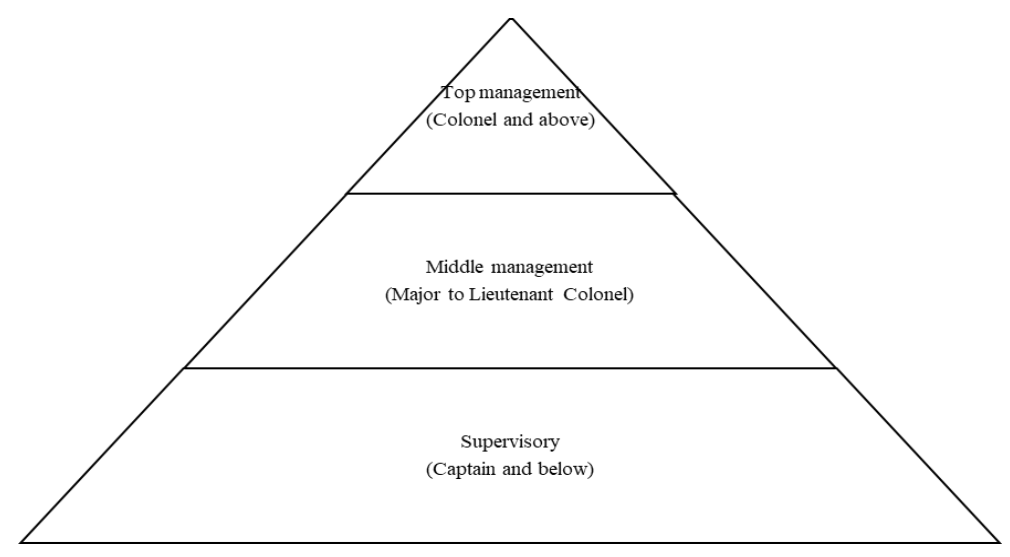

Figure 1. Army command system 


\section{Military doctrines}

Organizational communication in the military should be guided by the doctrines. The military doctrine is a collection of military's belief system regarding how the military understands, prepares for, and conducts military activities [41] and should be used as a guideline on how the military should communicate to achieve desired objectives. The selection of the communication medium to be applied in each activity must comply with the requirement in the military doctrine. As an example, the doctrine in the conduct of operational activities prohibits the use of unsecured mobile Internet communication to exchange operational information. This operational doctrine concerns on the security requirement. In the Command, Management and Leadership Doctrine published by Malaysia Army also stated that the commander needs to communicate with soldiers as part of the command function.

\section{Military regimental values}

The Military also has its own set of values called military regimental values. Military regimental values ingrained in the military minds and coating the behaviour and conduct of military personnel either at their workplace or in the social environment. The regimental values system tells how the officers and soldiers should communicate by following the command structure with full of respect according to their ranks. In certain situations, the commander also requires meeting their soldiers face-to-face to deliver instructions and thoughts. Routine daily orders for soldiers also only can be done in written form and cannot be shared in the online medium.

"Regimental System, where all Army personnel need to follow the system to maintain their high discipline quality, since obedience to the rules and tradition in the Army are key indicators for success, in all related tasks in the organization, besides the empowerment of character and appearance, since each personnel mirroring the image of Army that is respectful and highly-disciplined."- Army Chief, 2018

\section{Staff duties}

Finally, the culture of the Army organization exhibited in the use of staff duties convention in the writings. Staff duties convention tells the military personnel the right procedures of writing on different occasions for the military use. Each correspondence and document also having its way of using salutation, selection of words, and confidentiality level. Military personnel needs to ensure that the document received only by authorized personnel and the documents are classified according to its content. It is the responsibility of staff and military personnel in performing their actions including compliance to the service writing convention in handling documents and reports.

\section{METHODOLOGY}

The case study was conducted to study in-depth on the phenomenon of information systems used in the organization [42]. To study the suitability of MIM usage in the Malaysian Army environment, twelve Army officers from the rank of Major and Lieutenant Colonel were purposively selected for semi-structured interviews. They are experienced officers in their respective activities and having extensive exposure to the MIM usage at their workplace to communicate with their superiors and subordinates.

The data from the interviews were analyzed using thematic analysis [43]. The collected data from the interviews were extracted to the themes and were used for further analysis. From the analysis, the study found several issues related to the suitability of MIM usage in the Army working environment. For this paper, the suitability of MIM usage in the context of organizational culture will be explained in terms of challenges for the Army organization.

\section{DISCUSSION}

\section{The Challenges in Using Mobile Instant} Messaging in the Malaysian Army

Mobile technology such as MIM facilitates fast response in two-way communication either in person or group communication. MIM also having the ability to handle some verbal cues especially text and visual at minimum cost. These features allow fast sharing of information, concept, and ideas in the Army working environment. MIM also can be customized to suit the reporting requirement and the receiver's need. The use of MIM at the Army workplace assist officers and soldiers in many ways and boost their motivation through socialization at work. Despite all the benefits, the Army facing challenges on how to adapt this technology to ensure the benefit to the organization is maximized.

\section{Unsuitability of voice notes}

MIM cannot handle voice messages in the context of the Army environment even though the voice function is available and can be used in the channel [25]. The use of voice messages is minimal and not advisable in Army activities. It looks unethical in formal communication especially in the superior- 
subordinates relationship in the official occasion. The use of voice note is inappropriate due to formality at the military workplace which is bounded with military regimental values and command system. The use of voice notes also might disturb the conduct of combat training and operation activities.

\section{The absence of gestures}

There is a claim that people prefer to use text-based communication rather than face-to-face interaction [44]. This is also happening in the military organization since MIM is a suitable channel to carry meaningful text and symbols [45]. Anyhow, they find it difficult to using MIM to handle nonverbal cues. MIM is incapable of providing gestures and body language that are important in communication. Commander's gestures and emotions are important to be observed in the decision-making process. The gestures of subordinates are also important to prove their understanding of any delivered orders or instructions, especially in the training and operation environment.

Concerning non-verbal cues, the facial expression is important in communication where the sender can use emoticons or symbols as an addition to text to express their feelings [33]. That capability makes MIM a better alternative to face-to-face interaction in presenting emotions. In the Army organizational context, the emoji sign is inappropriate in formal communication even though it can represents emotion together with the text messages. Emojis assumed as a casual way of communication. Even though it is available in the MIM, but it not been used for work purposes in all activities since it portrays leisure communication and only accepted for leisure purposes.

\section{Limitation in carrying complex information}

Even though MIM is used widely as a medium to explain the concept and ideas through the user's preferred language as well as deliver the orders and instruction, but practically it is limited to the brief, simple and short contents. The study found that the soldiers were less interested in reading long and complex information through MIM. The absorption of information, concepts, and ideas becomes easier if the messages follow a standard format, short and in simple language. Additional to that, Army commanders preferably use face-to-face interaction to deliver their orders to suit military values and command requirements. Concept and ideas such as the commander's thoughts, opinions, and feedback on activities preferably to be shared face-to-face to avoid misinterpretation and can be integrated with the written form of communication.

\section{Potential of information leakage in groups}

Knowledge dissemination is important for high team performance [46] as well as in the military organization. Officers and soldiers usually work in teams and share the information through a group chat. In this situation, the possibility of information leakage and the sharing of classified information in the groups' chat must be taken as an important consideration. It should become a concern of military personnel to protect the confidentiality of information, especially in a wider group. The concern also arises when the users used MIM as a working diary and keep the records of communication for future reference [27].

\section{The sharing of classified contents}

MIM should be free from classified contents. Since the media capable of transmitting and fast sharing of photos, videos and multimedia [25], officers and soldiers at the training, operation and logistics activities usually share the contents related to their works with others through MIM. Some of the contents are confidential, sensitive and inappropriate. Despite the concern on the security, another concern exists when the Army staff starts to neglect the importance of clerical works in keeping the files and information. All the files and information were kept in the gadget storage.

\section{Reporting requirements}

Mobile messaging allows the customization of a message to suit the receiver and Army requirement including in the report submission and the handling of important documents. In a submission of reports and handling of documents, the users in the Army still need to follow the chain of command in the Army organizational structure and avoid the unstructured flow of documents. By not neglecting the capability of technology in carrying reports and documents, the military staff duties convention still needs to be preserved. The staff needs to follow the system of distributing documents and the receivers still need to acknowledge the receipient of a documents. It was found difficult if MIM was used where the flow of information could not be controlled and monitored.

\section{Concerns on the staff duties}

Customization of contents can be done in the MIM according to the user's need [44]. Through MIM, simple and short language can be used. Anyhow, MIM users were found neglecting the importance of using correct spelling, grammar, and words used. As an example, in the procurement activities, the use of numbers and technical names are important. There was a situation where the staff unintentionally share inaccurate figures in logistics calculation resulted in the bad decision by the commanders. In this situation, MIM usage will affect the decision- 
making process. Additional to that, according to the military staff duties, a military document must have security classification, systematic way or writings, and important documents must be authenticated before submitted to others. It was found difficult in MIM usage.

\section{Interruption and deviation of work focus}

In the work socialization aspect, MIM utilized as a social bonding tool through the engagement among officers and soldiers. In the Army environment, there are negative consequences relates to socialization such as the distraction of work focus when MIM is used such as interruption and deviation of work focus, exposure to many online activities, dragged to longer interaction and addiction. Nevertheless, in this situation, mobile technology such as MIM still considered a reliable medium to be used according to the benefits offered by that platform. There must be a good governance system as a control measure on the implementation of MIM in the Army workplace to minimize this socialization impact.

\section{CONCLUSION}

Mobile technology is a modern communication technology that offers a lot of advantages in the organizational communication. Anyhow in the actual application for the Malaysian Army use, it is bound by the practices and environment related to the Army culture; specifically its norms and values. The recognition of mobile technology as a communication channel in the Malaysian Army should be carefully implemented to guarantee the best return in terms of performance and productivity. The Malaysian Army faces a challenge to integrate the MIM with other communication media for success [47]. Good channels if effectively used will assist the Army personnel to perform a job better.

MIM can be capitalized to increase communication turnover and contribute to the success of the Army organization through interactive communication, to complete work tasks, and to coordinate work in all activities in a short time. The use of mobile messaging can boost officers' and soldiers' performances through the utilization of all cues in transmitting messages. Even though the use of nonverbal cues such as gestures and emotions are limited, verbal cues such as text, visuals, interactive multimedia, graphics, and videos can be maximized and can be integrated with other means of communication.

However, officers and soldiers need to careful in utilizing MIM to suit certain circumstances related with norms and values of military organizations.
The use of mobile messaging to convey concepts and ideas as well as to deliver orders and instructions should be tailored and customized according to the service's requirement. The use of standard language, well-structured writing, and suitable format would promote better understanding and at the same time preserve the staff duties requirement. The use of MIM to share classified information should be strictly prohibited.

The use of MIM as a social bonding tool is recommended but must be controlled and monitored to avoid overuse that can affect the execution of work tasks. The channel should not be used to discuss critical requirements for decision-making. The commanders must deliver his thought and order through face-to-face interaction in formal environments such as formal meetings and regimental parades. The information security and the protection of military values should become a priority in using modern technology in workplace communication.

\section{REFERENCES:}

[1] Walker, L. (Producer). (2017). The 10 Best Mobile Messaging Apps. Lifewire. Retrieved from www.lifewire.com

[2] Edwards, J. (Producer). (2012, Feb 13). The future of military comms on the battlefield. Defense System. Retrieved from https://defensesystems.com

[3] Ford, C. M. (2015, July-August). Army leadership and the communication paradox, Military Review, 68-73.

[4] Mansi, G. and Levy, Y. (2013). Do instant messaging interruptions help or hinder knowledge workers' task performance? International Journal of Information Management, 33, 591-596.

[5] Duke, É. and Montag, C. (2017). Smartphone addiction, daily interruptions and self-reported productivity. Addictive Behaviours Reports, 6 , 90-95.

[6] Montag, C. and Walla, P. (2016). Carpe Diem instead of losing your social mind: Beyond digital addiction and why we all suffer from digital overuse. Cogent Psychology, 3, 1-21.

[7] Suri, N.; Tortonesi, M.;Michaelis, J.; Budulas, P.; Benincasa, G.;Russel, S.; Stefanelli, C. and Winkler, R. (2016). Analyzing the applicability of Internet of Things to the battlefield environment. International Conference on Military Communications and Information Systems (ICMCIS), Brussels, Belgium, IEEE Conference Publication.

[8] Schein, E. H. (2004). Organizational culture and leadership (3rd ed.). San Francisco: Jossey-Bass. 
[9] Leidner, D. E., \& Kayworth, T. (2006). Review: A review of culture in information systems research: Toward a theory of information technology culture conflict. MIS Quarterly, 31(2), 357-399.

[10] Hofstede, G. H. (2001). Culture'sconsequences: Comparing organizations across nations. Beverly Hills, CA: Sage.

[11] Straub, D., Loch, K., Evaristo, R., Karahanna, E., \& Srite, M. (2002). Toward a theory-based measurement of culture. Journal of Global Information Management, 10(1), 13-23.

[12] Welch, M. and Jackson, P. R. (2007). Rethinking internal communication: a stakeholder approach. Corporate Communications: An International Journal, 12(2), 177-198.

[13] Cornelissen, J. (2014). Corporate Communication Theory and Practice. London: Sage.

[14] Bharadwaj, A., El Sawy, O. A., Pavlou, P. A. and Venkatraman, N. (2013). Digital business strategy: Toward a next generation of insights. MIS Quarterly, $37 \quad$ (2), 471-482.

[15] Proctor, T. and Doukakis, I. (2003). Change management: the role of internal communication and employee development. Corporate Communications: An International Journal, 8 (4), 268-277.

[16] Marlow, S. L., Lacerenza, C. N., Paoletti, J., Burke, C. S. and Salas, E. (2018). Does team communication represent a one-size- fits-all approach?: A meta-analysis of team communication and performance. Organizational Behaviour and Human Decision Processes, 144, 145-170.

[17] Keyton, J., Caputo, J. M., Ford, E. A., Fu, R., Leibowitz, S. A., Liu, T., Wu, C. (2013). Investigating verbal workplace communication behaviours. International Journal of Business Communication, 50 (2), 152-169.

[18] King, C. and Lee, H. (2016). Enhancing internal communication to build social capital amongst hospitality employees - the role of social media. International Journal of Contemporary Hospitality Management, 28 (12), 2675-2695.

[19] Jalalkamali, M., Ali, A. J., Hyun, S. S. and Nikbin, D. (2016). Relationships between work values, communication satisfaction, and employee job performance. Management Decision, 54 (4) 796-814.

[20] Gritsenko, V. (2016). Interaction on online forums and group communication: A case study of an IT support community. Paper presented at the International Conference on Communication in Multicultural Society
(CMSC 2015), 6-8 December, Moscow, Russian Federation.

[21] Oprea, C. and Stan, A. (2012). Adolescents' perceptions of online communication. Procedia - Social and Behavioural Sciences, 46, 4089-4091.

[22] Oghuma, A. P., Libaque-Saenz, C. F., Wong, S. F. and Chang, Y. (2016). An expectationconfirmation model of continuance intention to use mobile instant messaging. Telematics and Informatics, 33(1), 34-47.

[23] Gan, C. and Li, H. (2015). Understanding continuance intention of mobile instant messaging: motivators and inhibitors. Industrial Management \& Data Systems, 115(4), 646-660.

[24] Tang, Y. and Hew, K. F. (2017). Is mobile instant messaging (MIM) useful in education? Examining its technological, pedagogical, and social affordances. Educational Research Review, 21, 85-104.

[25] Tseng, F.-C., Cheng, T. C. E., Yu, P.-L., Huang, T.-L., \& Teng, C.-I. (2019). Media richness,social presence and loyalty to mobile instant messaging. Industrial Management and Data Systems, 119(6), 1357-1373.

[26] Wang, Y., Fang, W. C., Han, J. and Chen, N. S. (2016). Exploring the affordances of WeChat for facilitating teaching, social and cognitive presence in semi-synchronous language exchange. Australasian Journal of Educational Technology, 32(4), 18-37.

[27] Kaufmann, K. and Peil, C. (2019). The mobile instant messaging interview (MIMI): Using WhatsApp to enhance self-reporting and explore media usage in situ. Mobile Media \& Communication, 1-18.

[28] Couldry, N., and Hepp, A. (2017). The mediated construction of reality. Cambridge, UK: Polity Press.

[29] Pazos, P., Chung, J. M. and Micari, M. (2012). Instant Messaging as a task-support tool in Information Technology organizations. Journal of Business Communication, 50(1), 68-86.

[30] Zhang, S. and Fjermestad, J. (2008). Instant messaging: observations from two small ecommerce businesses. Journal of Enterprise Information Management, 21 (2), 179-197.

[31] Ling, R. and Lai, C.-H. (2016). Microcoordination 2.0: Social coordination in the age of smartphones and messaging apps. Journal of Communication, 66(5), 834-856.

[32] Karapanos, E., Teixeira, P. and Gouveia, R. (2016). Need fulfillment and experiences on social media: A case on Facebook and WhatsApp. Computers in Human Behaviour, 55, 888-897. 
[33] Kwon, O., Kim, C. R., and Kim, G. (2013). Factors affecting the intensity of emotional expressions in mobile communications. Online Information Review, 37 (1), 114-131.

[34] Lebbon, A. R. and Sigurjónsson, J. G. (2016). Debunking the instant messaging myth? International Journal of Information Management, 36, 433-440.

[35] Yin, P., Ou, C.X.J., Davison, R.M. and Wu J. (2018). Coping with mobile technology overload in the workplace. Internet Research, 28 (5), 1189-1212.

[36] Tung, M.-C., Huang, J.-y., Keh, H.-C. and Wai, S.-s. (2009). Distance learning in advanced military education: Analysis of joint operations course in the Taiwan military. Computers \& Education, 53, 653-666.

[37] Vijayakumar, P., Chang, V., Deborah, L. J. and Kshatriya, B. S. R. (2018). Key management and key distribution for secure group communication in mobile and cloud network. Future Generation Computer Systems, 84, 123-125.

[38] Kummer, T. and Schmeidel, T. (2016). Reviewing the role of culture in strategic Information Systems research: A call for prescriptive theorizing of culture management. Communication of the Association for Information Systems, 1 (5), 122-144.

[39] Maseng, T., Landry, R. and Young, K. (2010). Military communications. IEEE Communications Magazine (October), 50-52.

[40] Canary, H. (2011). Communication and organizational knowledge: Contemporary issues for theory and practice. Florence: KY: Taylor \& Francis.

[41] Jackson, P. A. (2017). The nature of military doctrine: A decade of study in 1500 words. Real Clear Defense. Retrieved from https://www.realcleardefense.com.

[42] Walsham G. (1995). Interpretive case studies in IS research. European Journal of Information System, 4, 74-81.

[43] Braun, V. and Clarke, V. (2006). Using thematic analysis in psychology. Qualitative Research in Psychology, 3(2), 77-101.

[44] Aharony, N. and Gazit, T. (2016). The importance of the Whatsapp family group: an exploratory analysis. Aslib Journal of Information Management, 68 (2), 174-192.

[45] Lee, Y., Kozar, K.A. and Larsen, K.R. (2009). Avatar e-mail versus traditional email:perceptual difference and media selection difference. Decision Support Systems, 46 (2), 451-467.

[46] Ou, C. X. J., Davison, R. M., Zhong, X. and Liang, Y. (2010). Empowering employees through instant messaging. Information Technology \& People, 23 (2), 193-211.

[47] Kuyath, S.J., Mickelson, R.A., Saydam, C. and Winter, S.J. (2013). The effects of instant messaging on distance learning outcomes. International Journal of Business, Humanities and Technologies, 3(2), 13-26. 